\title{
Notice to readers regarding the retraction note included in this issue
}

\author{
Kuniaki Tatsuta ${ }^{1}$
}

(c) The Author(s), under exclusive licence to the Japan Antibiotics Research Association 2022

Dear readers,

This is to inform you that the retraction note [1] included in this issue applies to a review article that was published online, but has not been included in any issue of The Journal of Antibiotics. A revised version of the retracted article was submitted to the journal, peer reviewed independently of the first version, and accepted. The revised, accepted review article [2] is included in this issue, Volume 75, Issue 2.

\section{References}

1. Zaidi AK, Dehgani-Mobaraki P. RETRACTED ARTICLE: The mechanisms of action of Ivermectin against SARS-CoV-2: An evidence-based clinical review article. J Antibiot. 2022; 75:122.

2. Zaidi AK, Dehgani-Mobaraki P. The mechanisms of action of ivermectin against SARS-CoV-2 - an extensive review. J Antibiot. 2022;75:60-71.
Kuniaki Tatsuta

tatsuta@waseda.jp

1 Waseda University, Tokyo, Japan 